\title{
OS SENTIDOS NA MÍDIA: O MST EM DOIS JORNAIS DIÁRIOS
}

\author{
Alexandre Bonetti Lima \\ Universidade Estadual de Londrina
}

RESUMO: Esta pesquisa objetiva participar da discussão sobre a mídia impressa a partir dos discursos sobre o MST do Pontal do Paranapanema em dois jornais diários. Ela situa-se no debate entre aquelas para as quais a mídia é um aparelho ideológico de dominação, e aquelas para as quais sua polissemia inevitável pode exercer participação construtiva numa sociedade de conflitos, mesmo sem intenção. A referência à Psicologia Social Construcionista nos localiza no segundo conjunto de reflexões, possibilitando contemplar o jornal diário como um mosaico no qual presentificamse múltiplas dialogias e produções de sentidos acerca dos temas noticiados, configurando-o, simultaneamente, como: veículo de transmissão de diversas vozes, oriundas de diversos lugares e com diversos posicionamentos sobre o que noticia; como ator social com voz e posicionamentos próprios sobre o mesmo; como lugar de diálogo com os leitores, co-autores ativos dos sentidos e histórias contadas. Mostra-se, portanto, como espaço de expressão da dinâmica das lutas hegemônicas de um tempo e lugar.

PALAVRAS-CHAVE: jornal diário; MST; discurso.

\section{THE MEANINGS IN THE MEDIA: THE MST IN TWO DAILY PERIODICALS}

ABSTRACT: This research aims to contribute to the discussion about printed media, studying the discourses of two daily newspapers concerning the MST - Movimento Sem Terra (landless rural worker's movement) from Pontal do Paranapanema. This work places itself in the debate between those positions that understand media as an ideological device of domination and those for whom the inevitable multiplicity of meanings from media may exert a constructive participation in a conflictive society, even though not intentionally. References to constructivist social psychology places our position in the second group of considerations and sees the daily newspaper as a mosaic in which multiple dialogues and meaning productions about the same theme coexist. This configures the newspaper in three simultaneous ways: as a means of conveying multiple voices, coming from different places and with different positions on what it reports; as a social actor, with its own voice and position about what it reports; and as a place to dialogue with readers, who are active co-authors of the meanings and stories that are told. Therefore, the newspaper appears as a space of expression of the hegemonic struggles of a certain time and place.

KEYWORDS: newspaper; MST; discourse.

Este artigo tem como objetivo contribuir para a discussão sobre a mídia impressa na modernidade a partir dos discursos na mídia impressa local e nacional sobre o Movimento dos Trabalhadores Rurais Sem Terra (MST) do Pontal do Paranapanema, região localizada a oeste do Estado de São Paulo (Brasil). Ele se situa no debate entre aqueles para os quais a mídia é considerada um aparelho ideológico de dominação e assujeitamento, e aqueles para os quais a polissemia inevitável do jornal e sua posição enquanto documento de domínio público pode exercer uma participação construtiva numa sociedade de conflitos - mesmo sem o querer. Nos alinhamos com o segundo conjunto de reflexões.

A escolha do MST do Pontal do Paranapanema como ator investigado nos jornais, entre as várias regiões nas quais o movimento dos sem terra tem base de ação, deu-se por ser onde o seu aparecimento mais provocou impactos nas relações de uso e propriedade da terra no país. Com cerca de um milhão de hectares de terras, sendo $90 \%$ delas de posse irregular (griladas), e apresentando índices de pobreza semelhantes aos das regiões pobres dos estados do nordeste, apesar de localizar-se no estado mais rico da federação, apresenta-se como lugar privilegiado para as ações do movimento.

O período em que acompanhamos a cobertura dos jornais sobre o MST do Pontal estendeu-se de 1990 (ano em que pela primeira vez apareceram matérias sobre o movimento nos jornais pesquisados) a 2000.

Os jornais que escolhemos como campo de investigação foram a Folha de São Paulo e O Imparcial, de Presidente Prudente, um jornal de circulação nacional e um regional, portanto. Tal opção se explica pelas diferenças de lugares de onde cada qual constrói suas notícias, cujos locutores, no primeiro (de circulação nacional), tendem a posicionar-se com mais distanciamento dos eventos noticiados sobre o movimento e, no segundo (o regional), por estarem bastante próximos dos mesmos (sendo, em geral, moradores da região), tendem a expressar - colados às 
notícias - seus interesses, preocupações, conceitos e preconceitos com mais intensidade e explicitude. Além disso, os jornais de grande circulação costumam ser menos rígidos com relação à sua linha editorial, sendo mais tolerantes às posições polêmicas, pois falam para um número bem mais extenso e heterogêneo de pessoas, espalhadas por vários pontos do país e, portanto, inseridas em redes sócioculturais diversificadas.

\section{Por uma concepção de discurso}

Uma vez definido o campo da pesquisa (os discursos sobre o MST do Pontal do Paranapanema a partir da Folha de São Paulo e de O Imparcial, de Presidente Prudente), foi preciso que decidíssemos por uma concepção de discurso. A concepção com a qual nos alinhamos faz referência à Psicologia Social Construcionista, o que nos leva a conceber o discurso não como representação ou tradução de algo (objeto, realidade, fato etc), mas como ação social. Decorre daí que separações entre ações sociais e palavras, entre real (concreto) e significação do real (palavras que o representam) são descartadas, pois discurso é ação, ação que dá sentido e materialidade ao mundo, às coisas, aos eventos e a cada um de nós em meio a tudo isso.

Para um dos autores de referência à literatura Construcionista, o filósofo da linguagem Mikhail Bakhtin, esse processo de produção de sentidos é sempre dialógico. Diz ele sobre isso:

A orientação dialógica é naturalmente um fenômeno próprio a todo discurso. Trata-se de uma orientação natural de qualquer discurso vivo. Em todos os seus caminhos até o objeto, em todas as direções, o discurso se encontra com o discurso de outrem e não pode deixar de participar, com ele, de uma interação viva e tensa (Bakhtin, 1988, p. 88).

Como conseqüência, todo discurso configura-se como uma entrançadura, como uma trama polidiscursiva, pois todo discurso é sempre perpassado pelo(s) discurso(s) de outrem(ns); ou seja, toda pessoa, mesmo quando em momentos de solidão reflexiva, "pensando com seus botões", ou escrevendo em seu diário íntimo "mensagens para si mesma", considera, conscientemente ou não, o discurso de outrem para confeccionar o seu. Ela é, assim, sempre respondente. De fato, diz Bakhtin:

Apenas o Adão mítico que chegou com a primeira palavra num mundo virgem, ainda não desacreditado, somente este Adão podia realmente evitar por completo esta mútua orientação dialógica do discurso alheio para o objeto. Para o discurso humano, concreto e histórico, isso não é possivel: só em certa medida e convencionalmente é que dela pode se afastar (1988, p. 88).

Procurando esclarecer melhor esta dialogia entre discursos e entre interlocutores(as), Bakhtin lança mão dos conceitos de voz e endereçamento. Com o conceito de voz, o autor explica que um discurso é sempre expresso através de uma consciência falante, com intencionalidades e uma visão de mundo; é sempre expresso através de uma voz. Porém, uma voz nunca é isolada, nunca é dissociada de outras vozes, ressalta; sua existência só é possível como resultado das interações com outras vozes; ela sempre produz um enunciado tendo como alvo certa direção, certo endereçamento, outra(s) voz(es), por assim dizer. Seja nas situações de diálogo face a face, onde ambas as vozes estão interagindo simultaneamente, seja nas situações de interação mediada (como nos jornais), ou solitariamente, em resposta a discursos imaginários ou internalizados, lidos ou ouvidos em algum momento da vida, todo(a) locutor(a) opõe sempre uma "contrapalavra", no dizer de Bakhtin, à palavra de outrem.

Com os conceitos de linguagens sociais e gêneros de fala, Bakhtin fornece uma visão ainda mais dinâmica do cotidiano das interanimações dialógicas. Pois, com eles, possibilita contemplar a presença simultânea das singularidades das consciências falantes (ouvintes e respondentes, compreensivas e compreensíveis) e das tipologias discursivas, ou seja, das normas e regulamentos discursivos formal ou informalmente - estabelecidos, conforme as circunstâncias de uso.

Contemplar o discurso como entidade performática, ou seja, como um tipo de prática social que se orienta em forma dialógica e multivocal, pressupõe enveredar também pelo terreno das relações de poder. Pois os processos de interanimação dialógica que se dão no cotidiano da existência de qualquer ser falante não são destituídos de tensões, embates, negociações em torno de interesses, crenças, valores, visões de mundo, em suma, não são destituídos de lutas de poder.

Norman Fairclough (2001, 2003), também um pensador da linguagem como Bakhtin, se utiliza do conceito de hegemonia para pensar a dimensão do poder nas práticas discursivas. Conceito originalmente desenvolvido pelo pensador italiano Antonio Gramsci, a hegemonia caracteriza-se por um equilíbrio instável e assimétrico entre uma classe ou categoria social sobre outra, mas que é sempre parcial e temporariamente alcançada, nunca definitivo. Para mantê-lo (o equilíbrio), o grupo dominante articulase em alianças e integra, através de algumas concessões, os grupos subalternos para seu campo de domínio (Gruppi, 1991). Tal processo deve ser continuamente alimentado e realimentado - e os elementos simbólicos das mídias têm papel crucial nisso - para não se romper, visto serem as relações de dominação/subordinação foco constante de lutas envolvendo um amplo conjunto de agências sociais, com seus variados interesses - econômicos, políticos, jurídicos, entre outros (Semeraro, 1999; Thompson, 1995). 


\section{O jornal como documento de domínio público}

Consonante com a concepção de discurso anunciada acima, a concepção de jornal com a qual nos alinhamos, já mencionada no início, o pressupõe como documento de domínio público. Melhor dizendo, com base nesta concepção entendemos o jornal como tendo a forma de um mosaico (McLuhan, 1962, 2001), no qual múltiplas falas justapostas acerca de cada assunto e de inúmeros assuntos presentificam-se, diariamente, ao longo de suas páginas. Como documento de domínio público, então, o jornal promove e veicula uma diversidade de falas que refletem o "ir e vir de versões circulantes assumidas ou advogadas" (Spink, 1999, p. 136) em cada tempo, mostrando-se, assim, como "lugar de construção coletiva de sentidos e histórias" (Martins, 2004, p. 66), onde continuamente formam-se novos personagens, renovam-se os antigos e confrontamse diferentes narrativas. Através do jornal podemos acompanhar os embates retóricos na busca pela hegemonia de sentidos, e no caso específico desta pesquisa, pela hegemonia acerca dos rumos da reforma agrária no Pontal do Paranapanema.

De fato, ao debruçarmo-nos sobre os jornais, pudemos notar uma variedade de vozes que diariamente presentificam-se nas suas páginas. Como diz Mouillaud (2002): "A respeito do jornal diário, não se poderia dizer que é um quarto de ecos onde ressoa o concerto de vozes que, sem ele, não teriam eco? Vozes discordantes por suas origens, seus conteúdos e seus locutores, caso sejam e devam ser autorizadas para se fazer escutar?" (p. 117). Assim, a título de exemplo, durante a gestão de Fernando Henrique Cardoso na Presidência da República do Brasil, não raro apareceram nos jornais matérias sobre o MST com referência ao então ministro da reforma agrária Raul Jungmann desqualificando o movimento dos sem terra como interlocutor legítimo na discussão da questão agrária. De outro lado, artigos com referência a personagens como José Rainha Jr. (um dos líderes do MST no Pontal do Paranapanema) posicionavam o mesmo movimento como interlocutor qualificado para essa discussão. Versões distintas, portanto, oriundas de vozes de lugares político-sociais distintos, dirigidas e sustentadas por intencionalidades igualmente distintas.

No entanto, além de um veículo que presentifica vozes oriundas de diferentes lugares e com diferentes intencionalidades, o jornal também é um ator social; e como ator social queé possui suas próprias versões e intencionalidades com respeito aos eventos que cobre. Tal pode se verificar não apenas nos artigos em que assume explicitamente suas posições (como os editoriais) como também nos dispositivos que utiliza em cada uma de suas matérias. A título de ilustração, nas matérias que, como no exemplo anterior, posicionam diferentemente o MST, pode-se perseguir o grau de verossimilhança e credibilidade de cada uma delas através de questões, como: em que páginas se localizam cada uma, da direita ou da esquerda? Qual a dimensão de cada uma? Que título levam? Que fotografias (se as há) ilustram as notícias? Como se desenha a arquitetura do texto? Em que conjunto de outros textos se insere o texto da notícia em questão? Em suma, que conjunto de referencialidades, que encenação da escritura há em cada uma e como se dispõem? (Mouillaud \& Porto, 2002) Elementos que forjarão mais ou menos verossimilhança e credibilidade às vozes de referência que falam.

A título de exemplo, atentemo-nos a dois artigos, de autoria do jornalista Edmilson Zanetti, publicados no dia 08 de março de 2000, na página A5, da editoria Brasil, do jornal Folha de São Paulo. No primeiro, a manchete é: "Cooperativa muda perfil dos sem terra", e diz:

As preocupações do MST com o gerenciamento de assentamentos e com as novas atividades econômicas contribuíram para um ano relativamente pacífico no Pontal do Paranapanema em 1999.

(...) O líder José Rainha Jr., conhecido pelos ataques verbais ao governo, hoje está calado, confinado a funções burocráticas no cargo de secretário da Cocamp (cooperativa agro-industrial dos sem terra do Pontal).

(...) Pelas mãos de 4218 famílias assentadas na região passaram quase R\$30 milhões entre 1995 e 1998. São recursos do governo para investimentos e custeio de safra. Das famílias contempladas, 2420 são associadas da Cocamp.

(...) Essa intensa atividade industrial transformou alguns dos mais radicais dirigentes do MST. Uns foram relegados a funções burocráticas, outros estão preocupados apenas com seu lote de terra.

A partir deste artigo, o jornal localiza a razão da reduzida presença do movimento em suas páginas durante o ano de 1999 na quietude do próprio movimento (foram apenas 20 matérias neste ano, contra 119 em 1998, 260 em 1997 e 216 em 1996), o qual, ainda segundo o jornal, vem se tornando uma organização cada vez mais capturada pelo mercado financeiro e pela burocracia administrativa, assumindo os assentados como prioridade e não mais os sem terra. Suas lideranças, afirma, ora voltadas para suas vidas privadas ("preocupados apenas com seus lotes de terra"), ora enredadas em atividades burocráticas (como Rainha na direção da Cocamp), nos leva a pensar em um MST que se falseia, pois seu nome (Movimento dos Trabalhadores Rurais Sem Terra) não mais condiz com sua realidade interna, e sua atuação trai seus princípios históricos, na medida em que prioriza os trabalhadores com terra. Ao apresentar o MST dessa forma, o jornal o desqualifica como voz crítica do sistema, já que o apresenta como capturado pelo mesmo, pela sua burocracia. Além disso, a legitimidade conquistada pelo movimento 
junto à opinião pública ao longo de sua curta história, deveu-se, em grande parte, por compor-se - organizando e sendo organizado - fundamentalmente, de famílias sem terra, miseráveis, excluídas do sistema produtivo e destituídas do acesso a bens de consumo mesmo básicos. Nãoé essa a realidade sócio-econômica dos assentados. Não mais.

Logo abaixo deste artigo, porém, outro há que se contrapõe, explicando, através de José Rainha Jr. - em tom de resposta - uma posição um tanto distinta da anterior. A manchete é: "É estratégia, afirma Rainha". Nele, há uma breve entrevista com José Rainha Jr., na qual o entrevistado (uma das principais lideranças do movimento na região) desmente a ocorrência de uma mudança de perfil entre os sem terra. Ele, de fato, confirma a maior importância dada agora pelo movimento ao gerenciamento dos assentamentos e da sua cooperativa, mas não a mudança de perfil acusada pelo jornal. Argumenta que os sem terra continuam fazendo ocupações e reivindicando um modelo de reforma agrária diferente do defendido pelo governo, por isso voltam-se para o melhor gerenciamento dos assentamentos que possuem, para mostrar à sociedade que mesmo em uma conjuntura bastante adversa, a reforma agrária que defendem é viável.

O jornal, assim, apresenta duas versões que posicionam distintamente o MST do Pontal do Paranapanema: a sua versão, por meio da qual descreve um MST bastante mudado, não mais aguerrido, radical e voltado para a conquista de novos assentamentos como antes, mas capturado pela burocracia do sistema financeiro e restrito aos problemas rotineiros da administração de assentamentos e da cooperativa de produção; e a resposta a ela, através de Rainha falando pelo movimento, por onde apresenta uma outra versão, a do MST que não mudou, mas apenas assumiu estrategicamente priorizar o gerenciamento dos assentamentos, tendo em vista a conjuntura adversa que se construiu para a agricultura familiar e cooperada viabilizar-se. Reagir a essa conjuntura para mostrar que a solução dos problemas agrários no país não se faz através do mercado é o mote desse "recuo estratégico", no dizer de Rainha.

Qual é a versão verossímil? Qual a mais crível? A disposição com que estão organizadas no jornal é bastante ilustrativa a respeito (Lima, 2005; Mouillaud \& Porto, 2000). O artigo posto na parte de cima é o que relata a versão do jornal. A resposta de Rainha, no outro artigo, situa-se abaixo. A dimensão do primeiro é aproximadamente duas vezes a do segundo. O mesmo ocorre com relação à dimensão das manchetes de ambos. No primeiro, há também uma fotografia de um agricultor trabalhando em um assentamento (seria uma referência ao argumento de que a população que exclusivamente interessa ao MST agora são os com terra?). Tal distribuição evidencia que o jornal, aqui, não expõe sua posição e a outra - diferente da sua-equilibradamente, como poderia parecer em uma primeira e desatenta leitura. Pelo contrário, ao ressaltar sua posição, sua fala sobre a do outro, organizando ambos os artigos da maneira como estão, referenda ainda mais sua voz, pois esta não está restrita ao conteúdo do primeiro artigo, mas atravessa toda a organização e a distribuição dos dois artigos - com a respectiva foto - na página. A voz do jornal, então, ressoa também no segundo artigo não apenas como aquela em relação a qual Rainha responde algo (uma negação: os sem terra não mudaram de perfil), mas na própria disposição com que a página é organizada, configurando um efeito comunicativo: os sem terra mudaram de perfil sim.

A desqualificação do Movimento dos Sem Terra como interlocutor político legítimo da reforma agrária, pela Folha de São Paulo, também se dá através do outros gêneros de fala. Assim, por exemplo, em artigo de 17/12/1995, publicado na página 15 da editoria da Revista da Folha pelo jornalista Armando Antenore, temos o seguinte:

Diolinda no pontal da fama.

Fosse um mês e meio antes, Diolinda Alves de Souza - líder dos trabalhadores sem terra no Pontal do Paranapanema - passaria despercebida. Mas naquela quarta-feira, 6 de dezembro, se encontrava em São Paulo justamente porque pretendia desfrutar da notoriedade repentina. Pela manhã, iria fazer fotos para a revista da Folha. À tarde, agendaria uma futura participação no 'Programa Livre', do SBT. À noite, estaria mais uma vez diante das câmeras: o 'Opinião Nacional', da TV Cultura, queria entrevistá-la ao vivo. No dia seguinte, conversaria com um repórter do jornal 'The New York Times'.

Miúda, cabelos curtíssimos, rosto quase adolescente, Diolinda, 25, ganhou a mídia por causa de uma polêmica decisão judicial. Em 30 de novembro, o juiz da da comarca de Pirapozinho (SP), Darci Lopes Beraldo, determinou a prisão de quatro membros do MST. O motivo: formação de quadrilha - crime que, sob a ótica do magistrado, comete quem incentiva a ocupação de propriedades alheias.

Atentando-se para a manchete da matéria ("Diolinda no pontal da fama"), o autor faz um jogo com a palavra pontal, de modo a produzir um desdobramento de sentido. Pontal, como sabemos, refere-se à região na qual Diolinda vive e milita pelo MST: o Pontal do Paranapanema. Mas, segundo o dicionário Aurélio, refere-se também à "altura de uma embarcação entre a quilha e o convés principal", definição que no conjunto da sentença em questão diz respeito à altura da fama por ela alcançada. Logo, o Pontal como referência do lugar de luta e militância pela reforma agrária a que Diolinda se dedica, desdobra-se - convertendo-se - em qualificativo para a fama que repentinamente ela alcança.

Seguindo em frente no texto, vemos que ele reacentua o que já anuncia na manchete. Descrevendo Diolinda em tom bastante informal - à maneira de uma conversa à mesa 
- como uma figura "miúda, cabelos curtíssimos, rosto quase adolescente", e apresentando a lista de compromissos que terá com a mídia nos próximos dias, o texto a posiciona quase como uma "pop star" do rádio ou televisão. Embora a identifique como líder dos trabalhadores sem terra no Pontal logo na primeira linha, não é este o enfoque que o texto toma como central, ou seja, o da sua atividade político-militante junto ao MST pela reforma agrária, mas sim as informações de sua vida privada, contando com a curiosidade popular em saber das fofocas do cotidiano de gente famosa. A Diolinda "miúda, cabelos curtíssimos, rosto quase adolescente", que mesmo perseguida por um juiz polêmico, conseguiu dar a volta por cima e ganhar a mídia, desfrutando, agora, "da notoriedade repentina" tende a produzir simpatia e afeição ao leitor, já que tornase um personagem com uma história bastante empática a ele. Ao mesmo tempo, porém, a Diolinda militante e líder do MST se secundariza, a Diolinda que traz atada em si a problemática da questão agrária e as marcas da história da luta do povo camponês fica sobreposta pela "pop star", apagando, assim, as marcas do MST de sua identidade.

Mas como afirmamos no início, um jornal, particularmente um jornal de grande circulação como a Folha de São Paulo, não se expressa de forma unívoca. Outras vozes, divergentes de sua linha editorial, embora em quantidade bem mais reduzida, também se apresentam. Assim, em artigo de 21/02/1996, a então deputada pelo Partido dos Trabalhadores (PT), Marta Suplicy, escreve na página 2A do caderno Brasil (editoria de política) um artigo com a seguinte manchete: "Sem medo dos sem terra: conhecendo a história". Neste artigo, ela apresenta um panorama do processo de grilagem na região, ou seja, do processo de apropriação irregular de terras públicas para uso privado pelos grandes latifundiários que ocorre desde a segunda metade do século XIX, procurando mostrar que os verdadeiros invasores não são os sem terra, mas os latifundiários grileiros. Ademais, a autora argumenta, expondo números expressivos, pelas melhorias que comumente os assentamentos promovem na situação sócio-econômica não apenas das famílias assentadas como também dos municípios do entorno, aumentando a arrecadação de ICMS pelas prefeituras e incrementando as trocas comerciais na região, com o aparecimento dos novos consumidores: os assentados.

Suplicy, ao escrever este artigo, o endereça a outros prévios direcionados ao MST, artigos que, via de regra, o denominam ora como invasor de propriedades alheias, ou como braço de organizações guerrilheiras, ou ainda como orientando-se por uma noção de reforma agrária ultrapassada, cuja concretização vai levar à favelização do campo, entre outras denominações que o desqualificam como interlocutor da questão fundiária no Pontal do Paranapanema - e, no país, por suposto. E em sua resposta, Suplicy utiliza de várias referencialidades discursivas para sustentar e incrementar seus argumentos, os quais orientam-se - e atuam, pois discurso é ação social - no sentido de re-significar o MST como agente importante no processo de reforma agrária e, por decorrência, da redução da pobreza e da tensão no campo. Seu artigo, portanto, permite vislumbrar uma historicidade interdiscursiva e uma interanimação dialógica no jornal, na medida em que traz consigo outros tantos discursos a partir dos quais se constitui.

Se a Folha de São Paulo, como se nota, apresenta com certa sutileza a sobreposição e maior ênfase de seus argumentos e de suas posições sobre outros argumentos e posições divergentes dos seus acerca da questão agrária e do MST do Pontal do Paranapanema, trazendo, com isso, a diversidade de vozes e posições sobre o tema, mesmo que desigualmente organizadas, não se pode dizer o mesmo do jornal O Imparcial, de Presidente Prudente. Neste, o MST é invariavelmente alvo de desqualificações sem quaisquer sutilezas. Posicionado como inimigo a ser extinguido, é satanizado em todos os editoriais que dele falam. Mesmo nas matérias no corpo do jornal, as nomeações com que é qualificado não são de modo algum elogiosas. E além da sua, as vozes que nele presentificam-se, embora variadas, via de regra fazem coro com suas posições, como a dos latifundiários, da Tradição, Família e Propriedade (TFP, organização católica extremamente conservadora), entre outras. Nas raras vezes em que vozes simpáticas ao MST são apresentadas, localizam-se ou em espaços menores do jornal, ou enredadas em referencialidades que as desqualificam. Como exemplo, vejamos o seguinte editorial, publicado em 24/08/1995:

Reforma agrária em solo infértil é caminho do bolsão da miséria

Não são conhecidos até hoje os objetivos reais do MST, articulado por corrente política que vem explorando a reforma agrária forçando aparentar propósitos sociais. Quem conhece o Pontal do Paranapanema não pode conceber honestamente que a área seja adequada para assentamentos de pequenos $e$ desvalidos agricultores. Qualquer estudo que se faça ali das propriedades das terras terá que concluir pela inviabilização da agricultura. O Pontal ainda não se transformou numa grande área desertificada porque seu solo é protegido por pastagens.

Comecemos pela manchete. Nela, se lê uma sentença afirmativa que aponta para a seguinte equação: reforma agrária em solo infértil = bolsão de miséria. Passando para o corpo do texto, nota-se que o solo infértil do qual fala a manchete diz respeito ao solo do Pontal do Paranapanema ("Quem conhece o Pontal não pode conceber que a área seja adequada ..."). Diante dessa afirmação, a indagação que faz o texto é sobre os verdadeiros objetivos do MST ao insistir na efetivação da reforma agrária, pois se o solo 
do Pontal é infértil, e se reforma agrária em solo infértil produz miséria, por que insiste o MST nessa empreitada? ("Não são conhecidos até hoje os objetivos reais do MST...”). A resposta a essa pergunta aparece na sequiência da mesma oração (“.... articulado por corrente política que vem explorando a reforma agrária forçando aparentar propósitos sociais"), na qual se depreende que, segundo O Imparcial, os objetivos que esconde o MST, por trás do aparente interesse social de reversão da pobreza através da reforma agrária, é um interesse político-ideológico, argumento que se repetirá em várias outras matérias sobre o MST. O texto é finalizado com duas orações em seqüência bastante elucidativas acerca da posição do jornal no embate fundiário MST X latifundiários. Na primeira oração ("Qualquer estudo que se faça ali ... terá que concluir pela inviabilização da agricultura"), argumenta pela impossibilidade do desenvolvimento da agricultura na região, dada a pobreza do solo para, na oração seguinte ("O Pontal ainda não se transformou numa grande área desertificada porque seu solo é protegido por pastagens") indicar a pecuária como forma ideal de produção nas terras do Pontal. Coincidentemente, esta é a forma de produção majoritária dos grandes latifundiários da região, cuja ação predatória - queimadas e uso de agente laranja para derrubada da mata a fim de preparar as ditas pastagens - foi responsável pelo empobrecimento do solo (e isso nãoé mencionado) (Fernandes, 1999, 2000; Lima, 2005).

Se os jornais mostram-se - embora de modos distintos - como atores sociais com posições e intencionalidades próprias no processo de participação da discussão sobre o MST e a questão fundiária no Pontal do Paranapanema, não quer isso dizer que os sentidos possíveis do que contam se encerram na sua produção final. Como documentos de domínio público que são, depois de produzidos e publicamente disponíveis, múltiplas possibilidades de sentidos são geradas nos processos de interpretação de suas matérias - e histórias - pelos leitores (Spink, 1999). Estes (os sentidos) são continuamente construídos e reconstruídos na medida em que as matérias são lidas, relidas e comentadas por diferentes pessoas, de diferentes lugares (Thompson, 1995, 1999). Decorre daí, que além de ator social contador de histórias, o jornal é um lugar de diálogo, e não apenas entre as vozes que estão nele presentificadas, mas também delas com o leitor, co-autor ativo das histórias contadas pelo jornal (Lima, 2005).

É nesse lugar, que movimentos sociais como o MST apostam suas fichas ao buscarem se fazer presentes nas páginas dos jornais - e de outras mídias. Embora conscientes das posições ideológicas que têm os jornais, cujas linhas editoriais são em geral contrárias a muitas das posições defendidas por eles, são conscientes também dos espaços - mesmo que mais reduzidos - deixados às vozes divergentes das da linha editorial, principalmente nos jornais de grande circulação, como a Folha de São Paulo.
Se com isso já se possibilita a circulação de vozes divergentes - embora desigualmente distribuídas-sobre o MST e os rumos da questão agrária no Pontal, ao se enfocar o lugar dos leitores, a variedade e divergência de vozes e de sentidos multiplicam-se. Com isso, o MST consegue trazer a discussão sobre a questão agrária para o espaço público, reorganizado e ampliado na modernidade com o advento das novas tecnologias e das comunicações mediadas (Giddens, 1991; Thompson, 1995, 1999).

É nesse lugar também (de leitor co-autor) que nos posicionamos para desenvolver esta pesquisa. Pois debruçarse sobre o jornal e analisar suas matérias é interpretá-las; e interpretá-las é utilizar-se de outros textos - acadêmicos e não acadêmicos, lidos, ouvidos, vistos - a partir de um lugar sócio-cultural e histórico, por onde se constrói um repertório interpretativo (Potter \& Wetherell, 1996), isto é, uma base para a leitura das matérias em questão. Nesse sentido, não se teve aqui a pretensão de penetrar na verdade essencial dos sentidos produzidos pelos jornais analisados, já que isso pressuporia a existência de leitores passivos, que absorvem homogênea e acriticamente as mensagens emitidas. Tencionamos, ao contrário, através de uma sistemática e atenta leitura, recontar as histórias contadas pelos jornais sobre o MST do Pontal do Paranapanema, buscando desvelar os personagens e vozes que falam e como falam (incluindo o jornal ele mesmo), os posicionamentos e lugares de onde produzem seus argumentos, as suas intencionalidades muitas vezes bastante sutis e presentes nos subtextos, os interdiscursos (isto é, a historicidade dos discursos, a quem respondem, ou se endereçam), as redes de poder e contra-poder (Bakhtin, 1999; Fairclough, 2001, 2003). Em suma, tencionamos com esta pesquisa continuar as conversas com os jornais e contar novas histórias, de modo a contribuir para reacender o debate de outro jeito, isto é, para mudar o tom do barulho deste cotidiano, o cotidiano do MST do Pontal do Paranapanema e toda a complexa, penosa e injusta situação agrária que o envolve.

\section{Referências}

Antenore, A. (17/12/1995). É Estratégia, Afirma Rainha. Jornal Folha de São Paulo, Revista da Folha, p. 15.

Bakhtin, M. (1988). Questões de literatura e estética. São Paulo: Hucitec.

Bakhtin, M. (1999). Marxismo e filosofia da linguagem. São Paulo: Hucitec.

Editorial (24/08/1995). Reforma Agrária em Solo Infértil é Caminho do Bolsão de Miséria. Jornal O Imparcial, Presidente Prudente, p. 2.

Fairclough, N. (2001). Discurso e Mudança Social. Brasília: Ed. UnB.

Fairclough, N. (2003). Analysing discourse: textual analysis for social research. London: Routledge.

Fernandes, B. M. (1999). MST: formação e territorialização. São Paulo: Hucitec. 
Fernandes, B. M. (2000). A Formação do MST no Brasil. Petrópolis, RJ: Vozes.

Giddens, A. (1991). As consequiências da modernidade. São Paulo: Ed. Unesp.

Gruppi, L. (1991). O conceito de hegemonia em Gramsci. Rio de Janeiro: Graal.

Lima, A. B. (2005). Era Uma Vez... Algumas Histórias: as versões sobre o MST do Pontal do Paranapanema em dois jornais diários. Tese de Doutorado não-publicada, Programa de Pós-Graduação em Psicologia Social, Pontifícia Universidade Católica de São Paulo. São Paulo, SP.

Martins, M. M. (2004). Milênios em uso: produção de sentidos globais e locais a partir de um jornal diário de grande circulação. Tese de Doutorado não-publicada, Programa de Pós-graduação em Psicologia Social, Pontifícia Universidade Católica de São Paulo. São Paulo, SP.

McLuhan, M. (1962). The Gutenberg Galaxy: the making of typographic man. London: Routledge.

McLuhan, M. (2001). Os meios de comunicação como extensões do homem (Understanding Media). São Paulo: Cultrix.

Mouillaud, M. (2002). O sistema das citações. In M. Mouillaud \& S. D. Porto (Eds.), O Jornal: da forma ao sentido (pp. 117-144). Brasília: Ed. UnB.

Mouillaud, M. \& Portpo, S. D. (Eds.) (2002). O Jornal: da forma ao sentido. Brasília: Ed. UnB.

Potter, J. E. \& Wetherell, M. (1996). El Análisis del Discurso y la Identificación de los Repertorios Interpretativos. In A. Y. Gordo \& J. Linaza (Eds.), Psicologías, discursos y poder (pp. 82-113). Madrid: Visor.

Semeraro, G. (1999). Cultura e educação para a democracia: Gramsci e a sociedade civil. Petrópolis, RJ: Vozes.

Spink, P. K. (1999). Análise de documentos de domínio público. In M. J. Spink (Ed.), Práticas discursivas e produção de sentidos no cotidiano (pp. 123-152). São Paulo: Cortez.
Suplicy, M. (21/02/1996). Sem medo dos sem-terra: conhecendo a história. Jornal Folha de São Paulo, p. 02.

Thompson, J. B. (1995). Ideologia e cultura moderna: teoria social crítica na era dos meios de comunicação de massa. Petrópolis, RJ: Vozes.

Thompson, J. B. (1999). A mídia e a modernidade: uma teoria social da mídia. Petrópolis, RJ: Vozes.

Zanetti, E. (08/03/2000). Cooperativa muda perfil dos sem-terra. Jornal Folha de São Paulo, p. A5.

Zanetti, E. (08/03/2000). É estratégia, afirma Rainha. Jornal Folha de São Paulo, p. A5.

Alexandre Bonetti Lima. Professor Adjunto do Departamento de Psicologia Social da Universidade Estadual de Londrina (UEL), Doutor em Psicologia Social pela Pontifícia Universidade Católica de São Paulo (PUC-SP). Endereço para correspondência com o autor: R. Vergílio Jorge, 600,

Jd. San Remo - Londrina (PR), CEP 86062-270, Fone: (43) 3371-4487; Fax: (43) 3371-4488.

bonetti@uel.br

\section{Os sentidos na mídia: o MST em dois jornais diários}

Alexandre Bonetti Lima

Recebido: 20/04/2006

$1^{\mathrm{a}}$ revisão: $15 / 06 / 2006$

Aceite final: 08/09/2006 